\title{
Caracterización de la red de innovación de pequeños productores ganaderos del estado de Sonora, México
}

\section{Social Network Analysis with small livestock producers in the state of Sonora, Mexico}

DOI: https://doi.org/10.17981/econcuc.40.2.2019.12

Artículo de investigación. Fecha de recepción: 09/09/2019. Fecha de aceptación: 22/10/2019

Adan Guillermo Ramírez-García

Universidad Autónoma Chapingo. (Ciudad Obregón, México)

gramirezg@taurus.chapingo.mx

\author{
Alejandro Ismael Monterroso-Rivas \\ Universidad Autónoma Chapingo. (Texcoco, México) \\ aimrivas@correo.chapingo.mx
}

Anastacio Garcia-Espejel

Universidad Autónoma Chapingo. (Texcoco, México) anastacio.espejel@gmail.com

Para citar este artículo:

Ramírez-García, A., Monterroso-Rivas, A. y García-Espejel, A. (2019). Caracterización de la red de innovación de pequeños productores ganaderos del estado de Sonora, México. Económicas CUC, 40(2), 195-216. DOI: http://dx.doi.org/10.17981/econcuc.40.2.2019.12

\section{Resumen}

Hoy en día el sector agropecuario enfrenta nuevos desafíos tecnológicos, organizacionales, institucionales, comerciales, de gestión, entre otros que pueden ser subsanados a través de la innovación, dada la importancia de lo anterior en el presente artículo se Caracteriza la red de innovación de pequeños productores ganaderos del estado de Sonora. El estudio fue llevado a cabo en el Distrito de Desarrollo Rural 149 Navojoa, el cual incluye los municipios de Huatabampo, Álamos, Etchojoa y Navojoa en Sonora (México). Se realizaron 62 encuestas a productores participantes en el Programa de Desarrollo de Capacidades, Innovación Tecnológica y Extensionismo Rural y a productores que no participan en el programa gubernamental, divididos en cuatro grupos: cooperantes, muestra, referidos y sin asistencia técnica. Se encontró que el índice de innovaciones es mayor entre los productores con asesoría constante por prestador de servicios profesionales. Las redes sociales identificadas incluyen la gestión, la comercial y la técnica. Los nodos que integran la red son 161 y la densidad es 5.40\%. Los principales actores son: productores, prestadores de servicios profesionales, comercializadores, instituciones gubernamentales y de investigación. Con lo cual se logró concluir que las innovaciones propuestas han incrementado en las UPP's desde que el programa inició su operación.

Palabras clave: Desarrollo rural; asistencia técnica; desarrollo de capacidades; innovación rural

\begin{abstract}
Today the agricultural sector faces new technological, organizational, institutional, commercial, and management challenges, among others that can be overcome through innovation, given the importance of the foregoing in this article. The innovation network is characterized of small livestock producers in the state of Sonora. The study was carried out in the Rural Development District 149 Navojoa, which includes the municipalities of Huatabampo, Álamos, Etchojoa and Navojoa in Sonora (Mexico). 62 surveys were conducted among producers participating in the Program for Capacity Development, Technological Innovation and Rural Extension and producers who do not participate in the government program, divided into four groups: cooperatives, sample, referrals and without technical assistance. It was found that the innovation rate is higher among producers with constant advice by professional service provider. The social networks identified include management, commercial and technique. The nodes that make up the network are 161 and the density is $5.40 \%$. The main actors are: producers, professional service providers, marketers, government and research institutions. Thus, it was concluded that the proposed innovations have increased in the UPPs since the program began its operation.
\end{abstract}

Keywords: Rural development; technical assistance; capacity building; rural innovation 


\section{INTRODUCCIÓN}

Bonilla, Cardeño y Cardeño (2015) dicen que "El encargado de la función financiera, en un mercado cada vez más competido, competitivo, y rodeado de un fuerte ambiente de incertidumbre, necesita pensar" (p. 141), por su parte Aguilar, Altamirano, Rendón y Santoyo (2010), comenta que la generación de riqueza en el sector agropecuario nacional enfrenta tres grandes desafíos: mejorar su competitividad y productividad; reducir la pobreza rural y aumentar la sostenibilidad de los recursos naturales.

El análisis de redes es una especialidad interdisciplinaria de la ciencia. Se basa en la observación de que los actores sociales son independientes y que los vínculos entre ellos tienen consecuencias importantes para cada individuo (Freeman, 2004).

Las innovaciones son creaciones nuevas con impacto económico, y puede ser de varios tipos: tecnológica, organizacional, institucional, comercial, de gestión, entre otras. A pesar de no existir consenso en el concepto de innovación, dos aspectos son comúnmente mencionados en las distintas definiciones: novedad y aplicación. De esta manera, una invención o idea creativa se convierte en innovación hasta que se utiliza para cubrir una necesidad concreta (Dorf, 2001).

Un aspecto crucial con respecto al alcance del concepto innovación se refiere al grado de novedad del cambio en términos del alcance geográfico. Así, un producto o proceso puede ser nuevo para un individuo de una región, de un estado o incluso de un país específico, pero no serlo para el mundo. Es más, el producto o proceso puede ser nuevo para un individuo de una región, pero no para otros individuos de la misma región; mientras para alguna determinada innovación ha devenido a "una buena práctica" (pues dejo de ser novedosa) y forma parte de un paquete tecnológico regularmente aplicado, en otros (quienes no la conocen o apenas la están conociendo y utilizando) aún se puede calificar como innovación.

Las innovaciones surgen de las interacciones complejas que se dan entre un conjunto diverso de actores públicos, privados y de la sociedad civil que se dedican a generar, intercambiar y utilizar el conocimiento dentro del denominado Sistema de Innovación Agrícola (AIS) (Spielman, Davis, Negash, $\&$ Ayele, 2008).

En este sentido, Engel y Salomon (1999), apuntan que la clave para la innovación agropecuaria, incluyendo la difusión y empleo de las innovaciones originadas por otros, radica en la calidad de la interacción entre los agricultores, empresas, donantes, investigadores y gobiernos. Con base en la afirmación anterior, la innovación no puede considerarse como una competencia individual, ni tampoco como la suma de una serie de competencias individuales; en lugar de eso, ésta debe verse como una competencia social, algo que comparten todos esos individuos, instituciones y organizaciones interesadas en el desarrollo rural. Además, Lundvall (2011) y Chumaceiro, Hernández, Meléndez y Acurero (2017) resaltan la importancia de la innovación como la capacidad de aprender y desarrollar competencias que promueve el emprendimiento y la iniciativa de mejora constante.

Cotec (2006) define la innovación como todo cambio basado en conocimiento que genera riqueza. Esta riqueza, entendida como la generación de satisfactores tangibles e intangibles, que se convierte en un factor determinante para la reducción de las brechas sociales existentes en el medio rural de México, donde la actividad agropecuaria es la principal actividad económica (Hernández y Chumaceiro, 2018) 
Muñoz, Rendón, Aguilar, García y Altamirano (2004) definenen las redes sociales de innovación como los grupos de individuos y/o organizaciones relacionadas en actividades o intereses comunes, las cuales se reflejan en flujos de información y de bienes; los principales componentes de dichas redes son los nodos, las relaciones y los flujos, cuyo análisis posibilita comprender cómo está integrado un sistema producto, el grado en que la red se encuentra organizada y los indicadores básicos que permiten fortalecer la competitividad de un sistema producto.

Se debe tener en cuenta que, la innovación es un proceso complejo que deriva y depende simultáneamente de dimensiones micro, meso y macro y que involucra a diversos agentes (Spielman et al, 2008).

La innovación relevante emerge de procesos de interacción social, haciendo necesario analizar la situación de flujos de información entre los diferentes actores y determinar los factores relacionados a este flujo de comunicación, para tomar decisiones orientadas al incremento de esta innovación (Hartwich y Ampuero, 2009). Es importante destacar que el modelo en red va más allá del modelo tradicional de innovación (Leeuwis y Van den Ban, 2004; Muñoz y Santoyo, 2010).

Cooke, Roper y Wylie (2003) señalan que el sistema de innovación está compuesto por dos subsistemas (subsistema de generación de conocimiento y el subsistema de explotación de conocimiento).

El análisis del Sistema de Innovación (SI) es una herramienta útil para ayudar a entender los procesos de innovación y difusión del conocimiento en el sector agrícola (Lamprinopoulou, Renwick, Klerkx, Hermans \& Roep, 2014). El reconocimiento de múltiples actores en los procesos de innovación y la interacción entre ellos ha llevado a los estudiosos del tema y a tomadores de decisión, a darle mayor importancia a la visión sisté- mica de la innovación (Van Mierlo, Leeuwis, Smits y Klein-Woolthuis, 2010).

Se requiere promover una organización agroempresarial capaz de activar potencialidades de aprendizaje e innovación en todas sus áreas operativas, así como redes de colaboración orientadas a esta última y apoyadas por las diversas instituciones y por un contexto institucional capaz de fomentar la innovación (Esser, Hillebrand, Messner $y$ Meyer-Stamer, 1996).

El papel del subsector pecuario en la economía estatal de Sonora son de gran relevancia socioeconómica y al igual que el resto del sector primario, ha sido base para el desarrollo de la industria agroalimentaria del Estado, proporcionando alimentos y materia prima, divisas, empleo y distribuyendo ingresos en el medio rural.

En Sonora, la producción de ganado bovino se realiza bajo dos sistemas de producción: 1) El extensivo que se desarrolla en los agostaderos que comprenden $83 \%$ de la superficie total del estado y se orienta en su mayor parte a la producción de ganado en pie, principalmente becerros y vaquillas para su exportación a los Estados Unidos; ésta actividad se realiza por 32 mil productores, con 1.5 millones de cabezas de ganado, en el cual gran parte de los criadores de becerros pertenecen al estrato de pequeños productores, con un hato inferior a los 30 vientres; con una producción inferior a las 15 cabezas de ganado al año y con una oferta que, además de atomizada es muy dispersa, situación que complica el acopio y comercialización de su producción. 2) El intensivo que se caracteriza por el confinamiento del ganado y alimentación balanceada con aplicación de tecnología de nutrición y genética animal. Su producción atiende la demanda de carne de alta calidad de Sonora y de otros estados del país. dispone de una capacidad instalada para la engorda de 145 mil cabezas al año y una ca- 
pacidad de procesamiento de 15 mil canales mensuales. Esta actividad ha disminuido su ritmo de producción, principalmente por problemas del alto costo financiero, insumos, altos costos de producción, sistemas deficientes de comercialización y competencia de carne importada (López, Solís, Murrieta y López, 2010).

Sonora ocupa, actualmente, el séptimo lugar en la producción de carne en canal de bovino, aportando el $4.3 \%$ de la producción nacional. Por otra parte, destaca la exportación de ganado en pie a los Estado Unidos de Norte América, cuyo promedio anual ha sido de 250 mil becerros, aunque en 2010 alcanzó las 300 mil cabezas, captando divisas por más de cien millones de dólares por año.

Los principales problemas que enfrenta la ganadería del estado son:

a. Sobrepastoreo: dadas las características climáticas, edáficas y de flora natural, la recomendación técnica para el pastoreo es de 28 ha por Unidad Animal (Semarnat, 2014). No obstante, Meraz y Zárate (2002), en un diagnóstico realizado sobre esta actividad económica, estimaron que había una sobrecarga promedio de $290 \%$. Dada la población ganadera actual y aun considerando las praderas existentes y los esquilmos agrícolas, difícilmente se cubren las necesidades forrajeras para evitar el sobrepastoreo.

b. Escasez de agua: la escasez de agua para abrevaderos en temporadas de estiaje es un problema recurrente y muy fuerte para el productor, repercutiendo en un incremento significativo de los costos de producción y la disminución de los rendimientos y puede llegar a la pérdida por muerte de los animales. La falta de agua de lluvia redunda en la disminución de la producción de forraje y recarga de acuíferos, problemas asociados a la compactación del suelo por sobrepastoreo. Este último problema se ha intensificado los últimos ocho años, provocando la muerte de ganado por falta de forraje y de agua para abrevar.

c. Organización de productores: la reducida organización de los ganaderos es una realidad que se manifiesta en la falta de aprovechamiento de programas de apoyo, ausencia de asistencia técnica, escasa infraestructura, venta y compra de productos a los intermediarios y deficiente manejo técnico de la ganadería (BorbónMorales, 2011).

Para hacer frente a estos problemas ya mencionados, la asistencia técnica pecuaria en el estado de Sonora hasta el año 2011 se realizó a través del modelo Grupos Ganaderos de Validación y Trasferencia de Tecnología-GGAVATT, cuya finalidad declarada era contribuir al desarrollo económico de la población, por medio de la formación de capital humano para fortalecer el desarrollo sustentable del subsector pecuario. Este modelo fue generado por el Instituto Nacional de Investigaciones Forestales, Agrícolas y Pecuarias-INIFAP entre 1983 y 1990, sus acciones promovían la intensificación del uso y adopción de tecnología pecuaria a través de proceso de validación y transferencia de tecnología en grupos organizados con fines de producción similares. Dichos procesos giran en torno a un módulo de validación en donde se utiliza y adopta la tecnología generada en los campos experimentales, con el objetivo de incrementar la productividad. Cada grupo es asesorado por un agente de cambio que recibe capacitación constante.

Sin embargo, en estudios realizados por INIFAP en 1997, y la Unidad Técnica Especializada Pecuaria anidad en el instituto, encontró que eran muy bajos los porcentajes de unidades de producción pecuaria (UPP) que adoptaron la tecnología, lo cual fue explicado 
en términos de los sujetos que operan el modelo, productores, prestadores de servicios y las instituciones gubernamentales de servicios y de investigación que participan en el proceso (INIFAP, 2010).

Para el caso de los productores, los factores que ocasionan la poca adopción son: baja escolaridad, edad avanzada, escasa infraestructura y equipo, desconocimiento y ausencia de manejo del mercado, baja eficiencia productiva y reproductiva; en tanto que para los Prestadores de Servicios Profesionales (PSP) se menciona el escaso compromiso para la generación de resultados, programas de trabajo alejados de las necesidades de los productores, desmotivación por el sistema de pagos, perfiles profesionales inadecuados para operar el programa, insuficiente actualización y desconocimiento de herramientas para una eficiente transferencia de tecnología; y para las instituciones de investigación se tiene escasa participación en la aplicación de tecnología en campo, recursos limitados, personal insuficiente (INIFAP, 2010).

Los problemas mencionados anteriormente permanecen en los diferentes programas de gobierno en los que subsidia a los productores para la contratación de asistencia técnica. Ello ocasiona los escasos resultados obtenidos en los componentes de Capacitación y Asistencia Técnica del ahora Programa de Desarrollo de Capacidades, Extensionismo Rural e Innovación Tecnológica, antes Programa Soporte (Secretaría de Agricultura y Desarrollo Rural-SAGARPA, 2012).

Con base en lo anterior, la Universidad Autónoma Chapingo a través del Centro Estatal de Capacitación y Seguimiento de la Calidad de los Servicios Profesionales de Sonora-CECS (Sonora), propuso la ejecución de la estrategia conocida como Centros de Servicios Ganaderos-CSG (RamírezGarcía, 2011; 2012; 2013).

\section{Metodología}

La población objetivo de este estudio fueron los productores del sur del estado de Sonora (México) ubicados en el Distrito de Desarrollo Rural 149 Navojoa, división administrativa de la Secretaría de Agricultura, Ganadería, Desarrollo Rural, Pesca y Alimentación (SAGARPA) y que comprende los municipios de Huatabampo, Etchojoa, Álamos y Navojoa. Con la intención de identificar las redes sociales de innovación en el sur de Sonora de los productores de ganado bovino del sistema producto carne, se realizaron encuestas semiestructuradas. El procesamiento de las encuestas incluyó la sistematización de la información, la codificación de variables, elaboración de bases de datos y creación de las variables de estudio. Para efecto de análisis estadístico algunas variables cualitativas se convirtieron a cuantitativas.

\section{Métodos para determinar la muestra}

El estudio se enfocó, en primera instancia, en una población de 240 ganaderos que recibían el apoyo del Programa Desarrollo de Capacidades, Innovación Tecnológica y Extensionismo Rural en el Componente Desarrollo de Capacidades y Extensionismo Rural. De este grupo de productores, quienes reciben el servicio de asistencia técnica, se eligieron a los subgrupos Muestra y Cooperantes. El subgrupo Sin asistencia técnica y el subgrupo Referidos fueron elegidos por el efecto bola de nieve. La clasificación de productores se basó en Rendón, Aguilar, Múñoz y Reyes (2007) y con el método estadístico. Los nombres de los productores que aparecían en la encuesta y que no fueron identificados por el modelo estadístico fueron elegidos con el método de bola de nieve y se catalogaron como Referidos (R) 
y fueron entrevistados hasta que el tiempo lo dispuso. Los límites del estudio fueron designados por el tiempo disponible.

La decisión tomada derivó porque son productores líderes en la actividad ganadera en la región y ya están identificados en todo el territorio de estudio.

La estrategia para seleccionar a los actores a entrevistar está ligada a los objetivos de la evaluación a emprender y el método de análisis de redes sociales de innovación. El método de selección es resultado de una combinación de herramientas de muestreo estadístico y no estadístico.

El muestreo estadístico se basa en la selección a azar de los elementos de una población definida, y se puede establecer la precisión y confiabilidad de las estimaciones realizadas.

Una de las virtudes de este proceso de selección es la oportunidad de identificar el grado de conexión existente entre los actores considerados como los más innovadores de la región y significa que por sí mismos tienen una elevada propensión a comunicarse y compartir sus conocimientos (Muñoz et al, 2004).

Los tipos de actores a encuestar se clasificaron como:

Productores Muestra $(M)$ : como parte de la operación del modelo de Centros de Servicios Ganaderos (Ramírez-García, 2011) los productores catalogados como Piloto y Seguimiento son prioridad para encuestar La población total de productores son 40 para cada categoría. De acuerdo con $\mathrm{Mu}$ ñoz et al (2004), la fórmula estadística se aplica para identificar la muestra de la población que recibe asistencia técnica. El tamaño de la muestra se calcula en la fórmula 1 :

$$
n=\frac{N Z^{2} S^{2} p}{N(\mu d)^{2}+Z^{2} S^{2} p}
$$

Dónde: $n$ : número de actores a encuestar; $N=$ número total de actores en la población, $d$ : precisión (expresada en proporción) $10 \%=0.1,5 \%=0.05 ; z$ : confiabilidad $($ para poblaciones mayores a 100 se pueden usar los siguientes valores: 95\%: 1.96, 90\%: 1.64; para poblaciones menores a 100 recurrir a los valores de la tabla de porcentajes de la distribución t de Student; S2p: varianza moderada de la población; $\mu$ : media de la variable muestral (Muñoz et al, 2004).

Productores cooperantes $(C)$ : los ganaderos, cuyo desempeño ha sido sobresaliente en términos de adopción de innovaciones, tanto a nivel local como regional, fueron seleccionados e identificados como Cooperantes. Estos productores se consideran importantes por su desempeño en las actividades en común en el ciclo de asesoría técnica. El número total de productores cooperantes fue de 40 y fueron elegidos sobre el número total de productores que reciben la asesoría técnica.

Productores sin asistencia técnica $(S)$ : el método consistió en elegir, estadísticamente, una muestra representativa de la población total de productores pecuarios en la región que no cuentan con asistencia técnica por el programa gubernamental, tomando como marco maestral el Censo Estatal para el Distrito de Desarrollo Rural 149 Navojoa. El tamaño de la muestra se calcula con fórmula 1.

Productores referidos $(R)$ : obtenidos como resultado del efecto bola de nieve (Rendón et al, 2007) y son aquellos actores locales quienes se reconocen como importantes para la cadena de valor bovinos carne en el territorio estudiado. Los nombres fueron mencionados por los productores identificados por los productores Muestra, Cooperantes y Sin asistencia técnica. A los encuestados se les pidió nombrar los lazos relacionales con fines de intercambio de información técnica, comercial o simplemente amistad (Muñoz et al, 2004). 


\section{Diseño del instrumento para colecta de datos}

El instrumento utilizado fue una encuesta. El diseño del instrumento contó con 7 apartados principales: atributos del productor, caracterización de la UPP, dinámica de la actividad, desarrollo organizacional, indicadores productivos, rentabilidad por la determinación de ingresos y costos, dinámica de la innovación y redes sociales.

\section{Captura de la información}

Las encuestas a productores, así como las relaciones referidas por los entrevistados con instituciones, se capturaron en Excel. El proceso de captura demandó un proceso ordenado y preciso. Los nombres de productores, empresas e instituciones se reemplazaron por códigos alfanuméricos para preservar la identidad de los informantes, respetando así el principio de confidencialidad que debe enmarcar toda investigación social.

\section{Análisis de información}

La exploración inicial de la información se dividió en tres secciones acorde a los datos contenidos en cada hoja de cálculo. Finalmente, el análisis de redes e intercambio de información entre los actores fue el eje central del análisis de este estudio.

El manejo de la información bajo el enfoque de redes sociales fue trabajado a partir del
Excel exportado a Bloc de Notas y posteriormente al programa UCINET. Con el uso de UCINET se extraen datos como centralidad, densidad y centralización de la red. Para centralidad y centralización: Network/ Centrality/Degree. Para la densidad: Tools/ Statistics/Univariate.

Para elaborar los gráficos de red se empleó el software NETDRAW. Con el uso de esta herramienta se dibujaron las redes por grupo de productores agregándose atributos para destacar aspectos relevantes tanto de los individuos como de las redes.

\section{Resultados y Discusión}

En la región de estudio se realizaron 62 encuestas; de los cuales, los productores Muestra fueron 26, los productores Cooperantes fueron 6 , los productores sin asistencia técnica fueron 26 y los referidos fueron 4. Fueron 54 productores referidos en total; sin embargo, solo 4 se entrevistaron; el tiempo de trabajo era insuficiente para entrevistar a todos. Sin embargo, en el análisis de redes de la gestión de la innovación se incluyeron todos los actores referidos.

\section{Atributos del productor}

El perfil sociodemográfico constituye una de las formas básicas e importantes para entender la realidad de una población y facilita la planificación de programas de intervención a nivel más básico.

TABLA 1.

Resultados sociodemográficos de los encuestados.

\begin{tabular}{llllll}
\hline \multirow{2}{*}{ Variable } & \multicolumn{5}{c}{ Promedio } \\
\cline { 2 - 6 } & Cooperantes & Muestra & Referidos & Sin Asistencia técnica & General \\
\hline Edad (años) & 50.50 & 53.96 & 49.75 & 54.27 & 53.48 \\
Escolaridad (grados) & 9.83 & 7.84 & 10.00 & 8.00 & 8.25 \\
\hline
\end{tabular}

Fuente: Elaboración propia basada en las encuestas realizadas. 
En general, los ganaderos son de edad muy avanzada. La edad avanzada representa un problema potencial para la continuidad de la actividad ganadera y tiene muchas implicaciones en la vida cotidiana en la comunidad, tanto a nivel individual, familiar y regional. Imaginar a la región sin actividad ganadera cuesta trabajo; la región tiene ascendencia en la producción de becerro en pie, principalmente, para la venta. La ganadería es una forma de vida en la región y es una de las principales fuentes de ingreso para la población del sector rural.

La actividad pecuaria requiere de mano de obra, misma que puede ser ocupada en los mismos núcleos de población en los que se está trabajando. Por lo que la actividad pecuaria, surge como una opción generadora de ingresos para muchas familias, y con esto, se pueden arraigar a su lugar de origen y evitar la migración. Por lo tanto, la ganadería también es una actividad de impacto social regional.
El modelo que explica la generación de empleos a partir del porcentaje de ingresos se explica por el siguiente modelo y gráfica (fórmula 2):

$$
y=-0.0149 x+1.9365
$$

Dónde:

$y=$ comportamiento de la variable Empleo con respecto a la variación del porcentaje de ingreso

$x=$ variación en el porcentaje de ingreso.

Según los datos, el modelo indica que no existe relación directa entre el porcentaje de ingresos y el número de empleos que genera, aun cuando, en números absolutos, quienes dependen en menor medida de la ganadería generan una mayor cantidad de empleos (38 empleos).

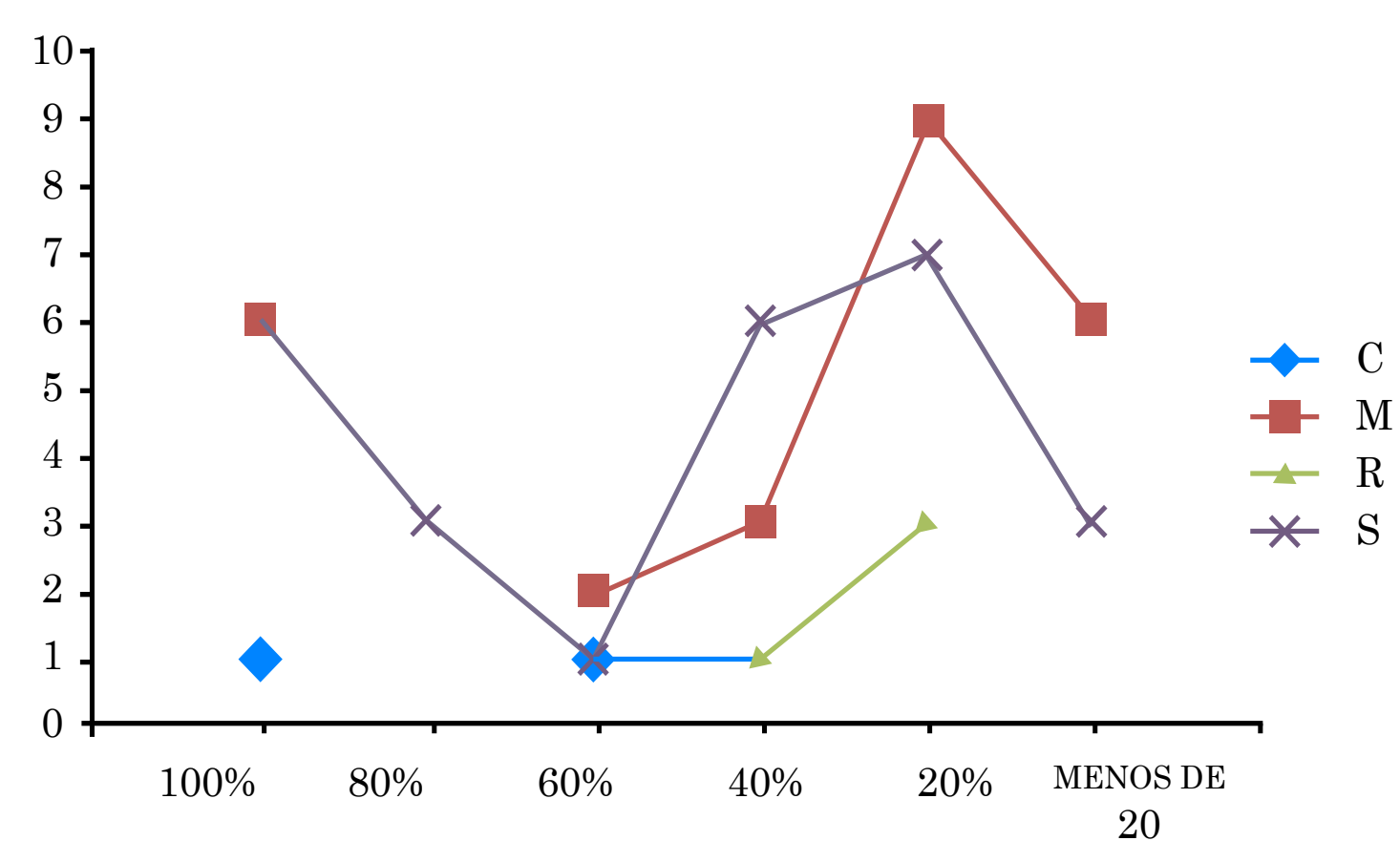

Figura 1. Empleos generados por categoría de ingreso derivado de la ganadería.

Fuente: elaboración propia con base en los resultados de las encuestas.

* Nota: C representa a los productores catalogados como Cooperantes, la M representa los productores Muestra, la S representa a los productores que no reciben asistencia técnica y son el grupo catalogado como Sin asistencia técnica, la $\mathrm{R}$ representa al grupo de productores catalogados como Referidos. 
La escolaridad de las personas encuestadas es considerada buena, puesto que, en promedio, todos, por lo menos, terminaron primaria y un poco más. Mención aparte para los productores Muestra que son los que demuestran menor grado de escolaridad y son quienes tienen mayor grado de avance en la disposición en la gestión de la innovación. En el caso de los productores Referidos son las personas con mayor grado de escolaridad y son, precisamente, los ganaderos que los demás reconocen como fuente de información para la adopción de innovaciones.

\section{Importancia de la actividad}

La importancia de la actividad para los productores del medio rural radica en la capacidad que éstos poseen para, a partir de la explotación y aprovechamiento de ganado bovino, obtener los satisfactores mínimos que coadyuven a la mejora en la calidad de vida de las familias que participan en esta actividad. La importancia de la actividad se establece como que porcentaje del productor lo obtiene a partir de la venta de los productos pecuarios.

Del total de productores encuestados, 13 productores reciben el 100\% de sus ingresos derivados de la actividad pecuaria; mientras, otros 20 ganaderos reciben más del 50\% de sus ingresos de la ganadería, lo que indica que, a pesar de la importancia de la ganadería en la región, los productores han buscado la diversificación en la fuente de ingresos; para un total de 31 productores que perciben menos del $20 \%$ de los ingresos por la ganadería. La mayoría de los productores por tanto requieren contratar a una persona que atienda al ganado. Lo que entonces promueve la generación de empleo en la zona rural.

\section{Red de conocimiento}

La gestión de la innovación, según resultados de las encuestas, se difunde en la región por los actores participantes en la red de valor, ya sea por asesores técnicos, otros productores y por la influencia de las dependencias gubernamentales y centros de investigación. Los datos arrojan, con certeza, la evidencia de un proceso de intercambio de experiencias y aprendizajes. Sin embargo, el grado de interacción entre actores depende, además de atributos del productor, de la capacidad y habilidad de integrarse a las nuevas tecnologías que se generan en el entorno y que pueden ser adoptadas por cada uno o por la colectividad. Así, los resultados demuestran que el índice de adopción de innovaciones es resultado no solo de las capacidades de innovación, sino también de la posición de cada grupo en la estructura general de la red (Muñoz et al, 2004). Las interacciones ocurridas al interior de cada grupo y entres los grupos se basan en la transferencia del conocimiento basado en el contacto directo y la comunicación directa entre los actores y el desarrollo de las relaciones.

\section{Arquitectura de la red bovinos carne en el Sur de Sonora}

La red que se presenta en este estudio se constituye de 62 productores. Con fines de análisis, se presentan subredes de interacción de gestión, comercial y técnica. Este análisis deriva de la necesidad de observar de manera la interacción entre productores. Se nota que un mismo actor puede aparecer simultáneamente en dos subredes al ser referido como fuente de información técnica y como comprador (red comercial). La esquematización de los actores en las subredes se presenta a continuación. 


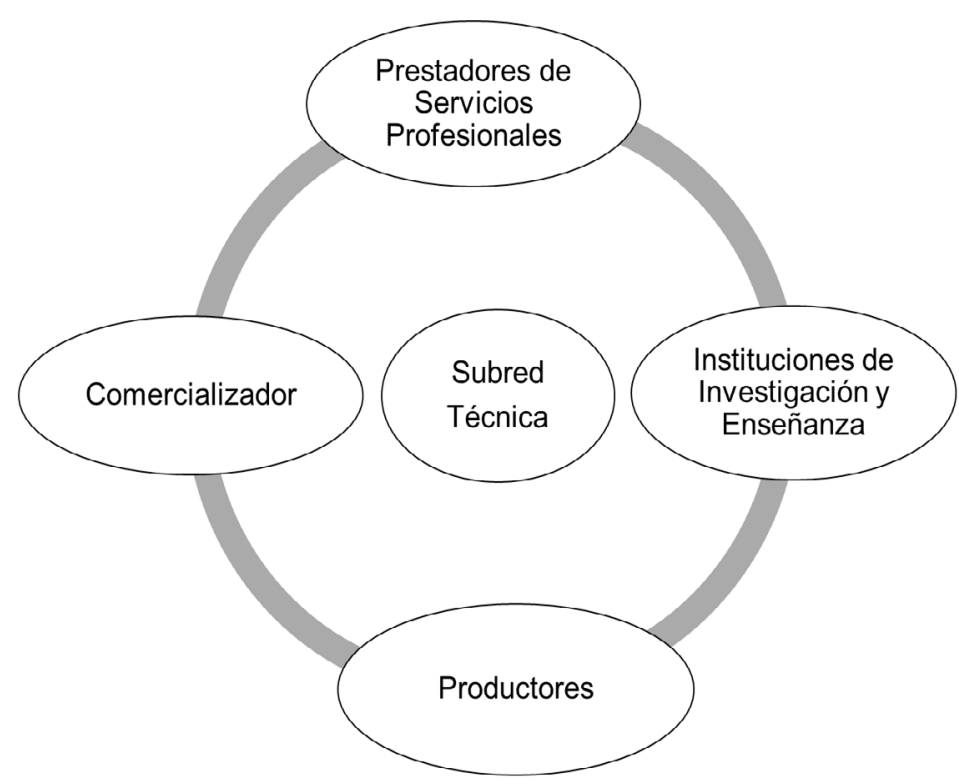

Figura 2. Esquematización de actores que participan en la subred técnica.

Fuente: Elaboración propia con base en las encuestas.

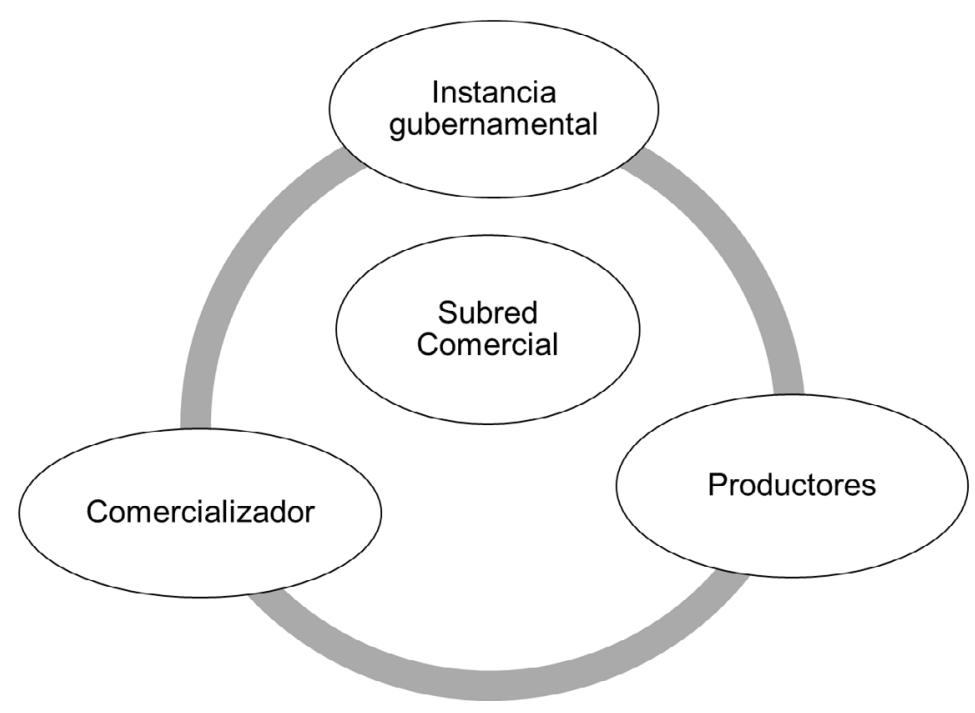

Figura 3. Esquematización de actores que participan en la subred comercial.

Fuente: Elaboración propia con base en las encuestas.

Los actores que participan en la subred técnica son: productores, que son los principales actores en la red de asesoría técnica al ser quienes reciben el apoyo gubernamental; el comercializador es el actor que, funge como comprador del becerro producido por el ganadero, pero también, en muchas ocasiones ayuda a los ganaderos a producir por los vínculos constantes entre ambos ac- tores y porque también, una merma en la producción de becerros le afecta su negocio; los PSP son los encargados de brindar la asesoría técnica al productor y están contratados por el programa de la SAGARPA; y las instituciones de enseñanza son quienes, en primera instancia, las responsables de generar las innovaciones para luego ser transferidas al sector social ganadero. 
Los actores que participan en la subred comercial son: los productores quienes aportan el becerro de 150 y hasta $180 \mathrm{~kg}$ en pie y entregados a pie de corral o en instalaciones de la Asociación Ganadera Local; los comercializadores son aquellos que movilizan y agilizan el proceso de venta del becerro en pie desde las praderas o a pie de corral y facilitan la capitalización del campo; los productores mencionan las instituciones gubernamentales porque, por ejemplo, el SIINIGA, que es la instancia que brinda certeza sobre la posesión del ganado, es necesaria para cada movilización de ganado por el productor. En esta subred, la participación del comercializador es importante porque no solamente compra el becerro; en muchas ocasiones, el comercializador capitaliza el sector mediante créditos a la comercialización directamente con el ganadero y ayuda a solventar las necesidades primarias: compra de alimento en época de estiaje, reparación de cercos y mantenimiento de la infraestructura agropecuaria, mantenimiento de la sanidad animal y movilización del ganadero cuando no hay flujo de capital entre las temporadas de venta de ganado.
La subred de gestión se entiende como la participación de los actores en acciones orientadas a gestionar labores colectivas: organización de productores para la compra/venta consolidada, acciones colectivas para la gestión de recursos financieros o subsidios a la actividad ganadera. Incluso, la gestión sobre el adecuado manejo de los recursos naturales en el agostadero forma parte de la organización que se realiza en el territorio. Los actores que participan en la subred de gestión realizan las siguientes actividades: los productores son el eje central de la gestión porque son ellos los principales beneficiarios y los actores sobre los que recae la mayor responsabilidad en el territorio, los PSP que son los agentes de cambio inmersos en el territorio y son quienes son los responsables directos de ayudar y apoyar a los ganaderos para acceder a la información actualizada y más oportuna para ellos, las instancias gubernamentales participan en la subred porque aportan metodologías de apoyo al PSP o porque son las instancias ante las cuales los productores acuden a realizar sus gestiones. La subred de gestión es la red con menor integración, precisamente por la dispersión de los ganaderos y por la cultura fomentada en

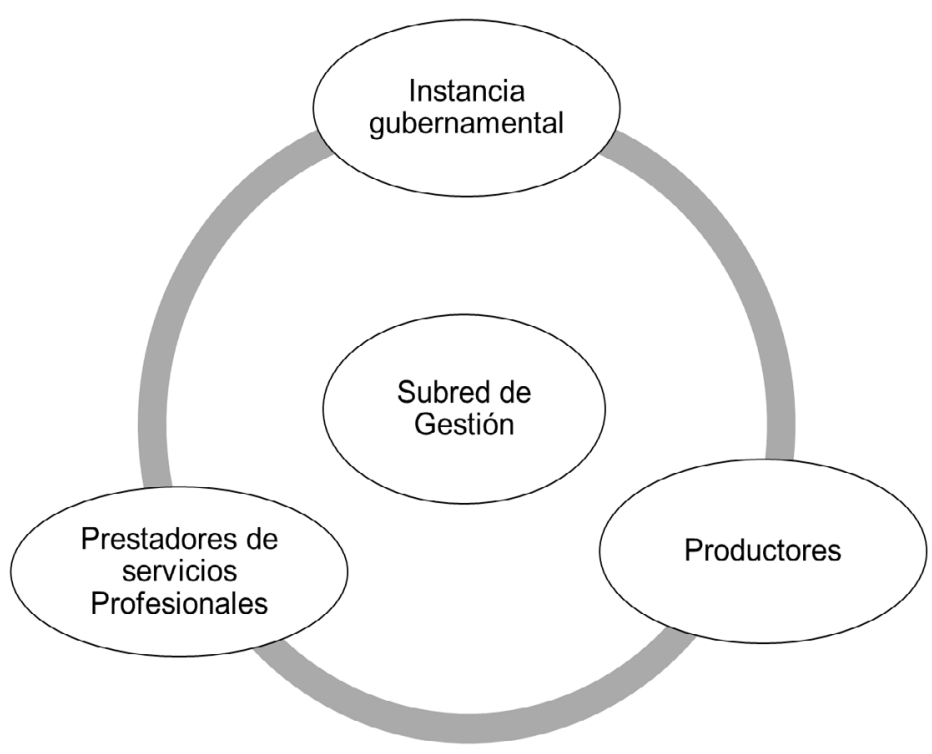

Figura 4. Esquematización de actores que participan en la subred de gestión.

Fuente: Elaboración propia con base en las encuestas). 
la región donde se privilegia el individualismo en lugar del colectivismo.

\section{Indicadores de centralidad de las subredes}

Considerando que las redes están definidas por sus actores y las conexiones existentes entre ellos, es pertinente comenzar el análisis examinando las propiedades básicas de la red: número de actores, conexiones existentes con relación a las posibles, así como la orientación de las relaciones. Para determinar todos los indicadores mencionados, el programa Key Player fue utilizado. Es fundamental identificar el grado de conexión entre los actores, la integración de la red. Así, muchas conexiones indican la posición de los actores ubicándolos con mejores posibilidades para mover recursos y resolver problema.
Solo 4 productores referidos fueron entrevistados, por tanto, no se precisa los datos de salida, toda vez que no es representativo del total. Para hacerlo más completo, se deberá dar continuidad al estudio a fin de complementar dicha información.

Los datos señalan que el subgrupo Muestra son aquellos con mayor acercamiento hacia con los demás actores de la red (3.88\%); esto puede derivar de la presencia de un asesor que ha favorecido el fortalecimiento de las relaciones sociales, productivas y de conocimiento. Asimismo, el subgrupo Muestra, también, son el grupo más conectado con los actores de la red, siendo importante, ya que son quienes reciben de manera permanente la asesoría técnica del programa gubernamental.

Los productores de la categoría Sin asistencia técnica están en menor contacto con los actores de la red en las diferentes sub-

TABLA 2.

Media del grado de centralidad para las subredes comercial, gestión y técnica.

\begin{tabular}{|c|c|c|c|c|c|c|}
\hline \multirow{2}{*}{$\begin{array}{c}\text { Grupo de } \\
\text { productores }\end{array}$} & \multirow{2}{*}{$\begin{array}{c}\text { Grados de } \\
\text { centralidad (\%) }\end{array}$} & \multicolumn{5}{|c|}{ Subred } \\
\hline & & General & $\begin{array}{l}\text { Con asistencia } \\
\text { técnica }\end{array}$ & $\begin{array}{l}\text { Sin asistencia } \\
\text { técnica }\end{array}$ & Comercial & Gestión \\
\hline \multirow[b]{2}{*}{ Muestra } & Grados de salida & 3.880 & 3.995 & 3.757 & 1.285 & 6.790 \\
\hline & $\begin{array}{l}\text { Grados de } \\
\text { entrada }\end{array}$ & 2.216 & 2.5 & 2.773 & 2.380 & 0.0 \\
\hline \multirow[b]{2}{*}{ Cooperantes } & Grados de salida & 3.333 & 3.030 & 3.081 & 1.190 & 1.667 \\
\hline & $\begin{array}{l}\text { Grados de } \\
\text { entrada }\end{array}$ & 1.563 & 2.273 & 2.521 & 1.190 & 0.0 \\
\hline \multirow[b]{2}{*}{ Referidos } & Grados de salida & 0 & 0 & 0 & 0 & 0 \\
\hline & $\begin{array}{l}\text { Grados de } \\
\text { entrada }\end{array}$ & 1.750 & 2.121 & 2.353 & 0.0 & 0.0 \\
\hline \multirow{2}{*}{$\begin{array}{l}\text { Sin } \\
\text { asistencia } \\
\text { técnica }\end{array}$} & Grados de salida & 3.580 & 3.907 & 3.782 & 1.381 & 0.0 \\
\hline & $\begin{array}{l}\text { Grados de } \\
\text { entrada }\end{array}$ & 1.458 & 1.641 & 1.821 & 1.190 & 0.0 \\
\hline
\end{tabular}

Fuente: Elaboración propia con base en los resultados del análisis del software y las encuestas. 
redes; esto indica que, sin la presencia de un asesor, se limita el desarrollo productivo, inclusive disminuye el acceso a programas de apoyo al campo (observar datos de la red de gestión: 1.19), muy probablemente se deba a que la información no se recibe con oportunidad y pertinencia. En este dato permite observar el efecto positivo del programa gubernamental entre los pequeños productores.

Los productores cooperantes priorizan más las relaciones de tipo social, tanto para dar como para recibir algún beneficio de la red. Los productores Muestra y los Referidos privilegian los vínculos sociales cuando de emitir información se trata, pero cuando se plantean la necesidad de recibir algo de la red, los del grupo de productores Muestra tienden a estrechar lazos con los asesores técnicos.

Analizando la red Sin asistencia técnica contra la red de Con asistencia técnica (se elimina el efecto del asesor con el grupo y como fuente de información) se corrobora que los productores que reciben la asesoría del programa gubernamental son quienes destacan como líderes en la adopción de innovaciones. Se asevera que las relaciones técnicas, entre los subgrupos de productores, son de vital importancia y lo son porque el programa gubernamental las impulsa; mientras, las relaciones comerciales no son importantes entre los subgrupos analizados, ya que la tradición en la población es no realizar actividades consolidadas.

Para los cuatro subgrupos de productores definidos, las relaciones comerciales y la red de gestión se encuentran en un estado incipiente, concluyendo que tanto vendedores, centros de enseñanza e investigación, dependencias gubernamentales se encuentran relativamente aisladas de la red de gestión, priorizando cuestiones técnicas entre los actores.

\section{Tamaño y densidad de la red}

La densidad de la red es la proporción de relaciones existentes con respecto a las posibles, atendiendo que entre mayor sea la cantidad de actores mayor será la dificultad para lograr las relaciones y al mismo tiempo, para construir y mantener los lazos de comunicación.

Así, la subred de gestión es la más pequeña (se integra con 19 actores: incluyendo principalmente productores del subgrupo Muestra y del subgrupo Sin asistencia técnica con distintas instituciones de gobierno) y también la más compacta (densidad $=9.36 \%$ ); por el contrario, la subred de los productores con el efecto de la asistencia técnica logra un $5.49 \%$ de relaciones posibles, disminuyendo a un $4.83 \%$ con la densidad de aquella red que se elimina el efecto de la asesoría técnica. Por otra parte, se observa que la subred comercial es la más desconectada, lo que proporciona elementos para proponer asesoría técnica para impulsar la organización de productores que busque la concretización de estrategias de venta que beneficien a la mayoría de los pequeños productores.

Donde la O representa a las organizaciones que participan en la red; la M representa los productores Muestra, la C representa a los productores catalogados como Cooperantes, la $\mathrm{S}$ representa a los productores que no reciben asistencia técnica y son el grupo catalogado como Sin asistencia técnica, la $\mathrm{R}$ representa al grupo de productores catalogados como Referidos, la S representa a los productores que no reciben asistencia técnica y son el grupo catalogado como Sin asistencia técnica, la T representa a los asesores técnicos o PSP, la V representa a los comercializadores que participan en la red de análisis. A continuación, las gráficas de las redes identificadas se muestran a continuación. 
La red completa se integra por 161 nodos y una densidad de 5.40\%. Esto quiere decir que existe gran dispersión entre los actores y que algunas estrategias de formación de colectivo para mejorar la capacidad de movilidad de información e incrementar la capacidad de innovaciones en la red.

Donde la $O$ representa a las organizaciones que participan en la red; la $\mathrm{M}$ representa los productores Muestra, la $\mathrm{C}$ representa a los productores catalogados como Cooperantes, la $\mathrm{S}$ representa a los productores que no reciben asistencia técnica y son el grupo catalogado como Sin asistencia técnica, la $\mathrm{R}$ representa al grupo de productores catalogados como
Referidos, la $\mathrm{T}$ representa a los asesores técnicos o PSP, la V representa a los comercializadores que participan en la red de análisis.

La red comercial se compone de 85 actores y la densidad es de $4.57 \%$. En esta subred se aprecia la posibilidad, muy amplia, de la formación de colectivos para la comercialización conjunta; además, se observa que los nodos, en muchos casos, no se integran de forma organizada, sino que se aíslan. Esto quiere decir que los productores y los comercializadores tienen muchas opciones para fortalecer esta red y propiciar el incremento en los beneficios para el sector y en la región.

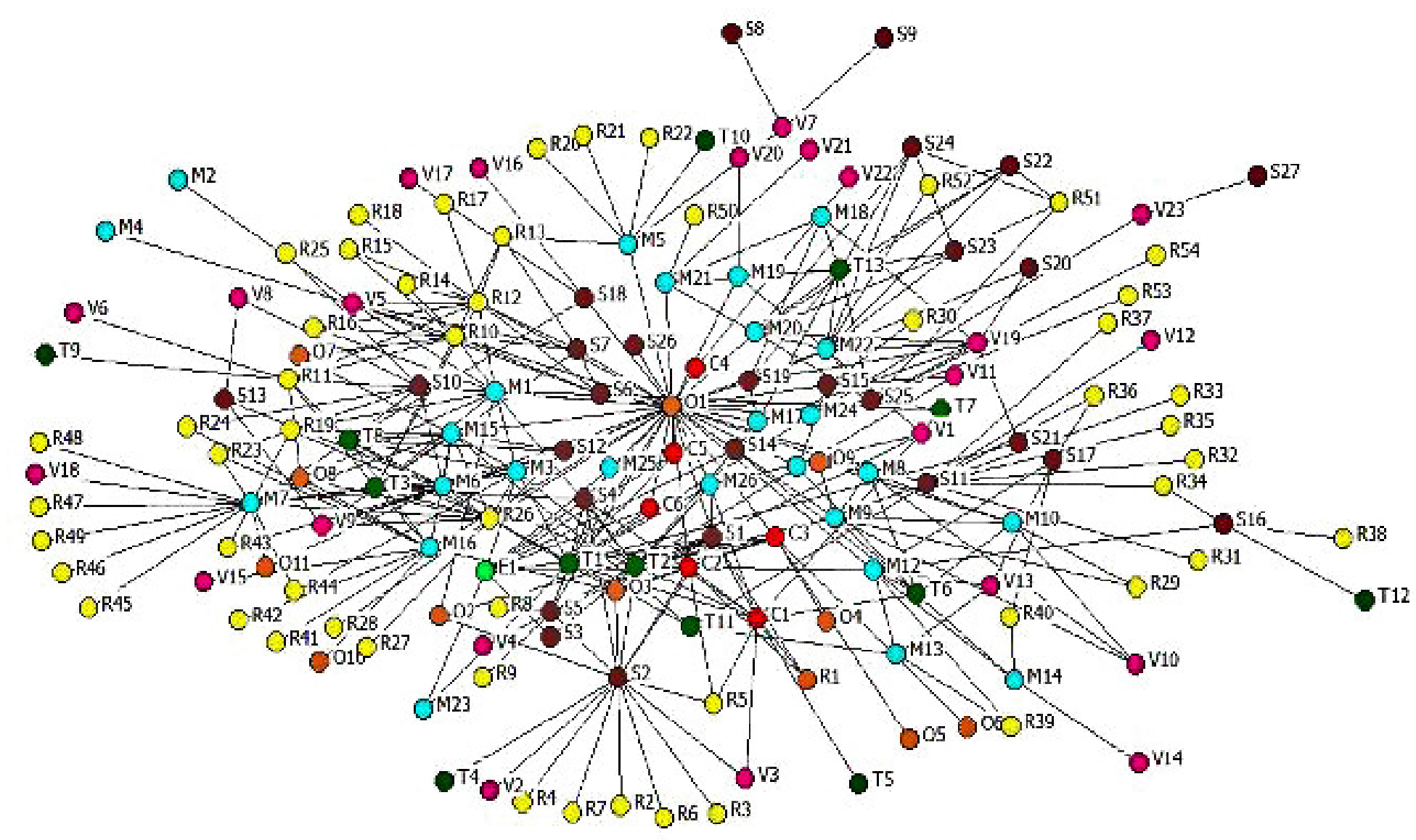

Figura 5. Interacción de los nodos identificados de la red de ganadería de bovinos carne en el DDR 149 Navojoa.

Fuente: Elaboración propia con base en las encuestas. 

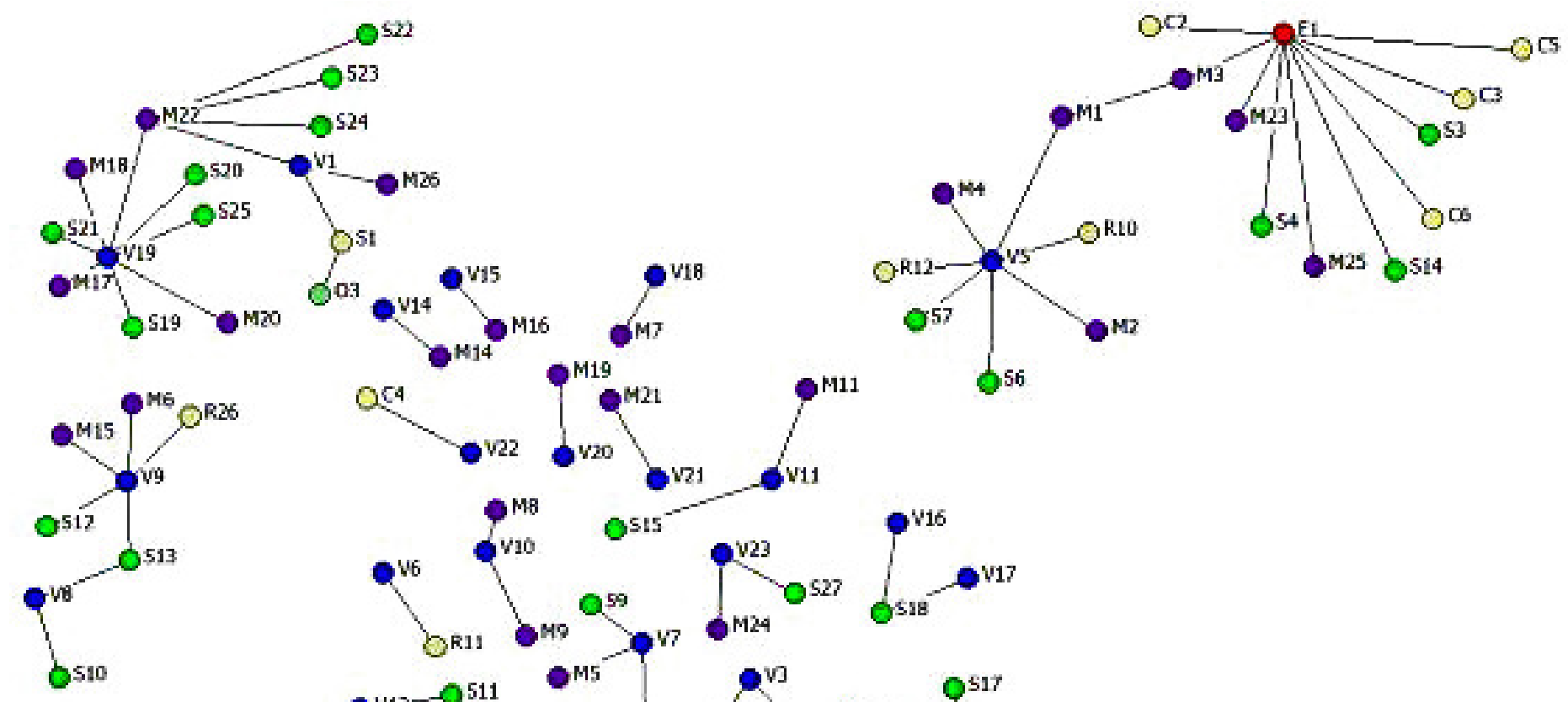

Figura 6. Esquema de la red comercial

Fuente: Elaboración propia con base en las encuestas.

"Nota: La O representa a las organizaciones que participan en la red; la M representa los productores Muestra, la C representa a los productores catalogados como Cooperantes, la $\mathrm{S}$ representa a los productores que no reciben asistencia técnica y son el grupo catalogado como Sin asistencia técnica, la $\mathrm{R}$ representa al grupo de productores catalogados como Referidos, la V representa a los comercializadores que participan en la red de análisis.

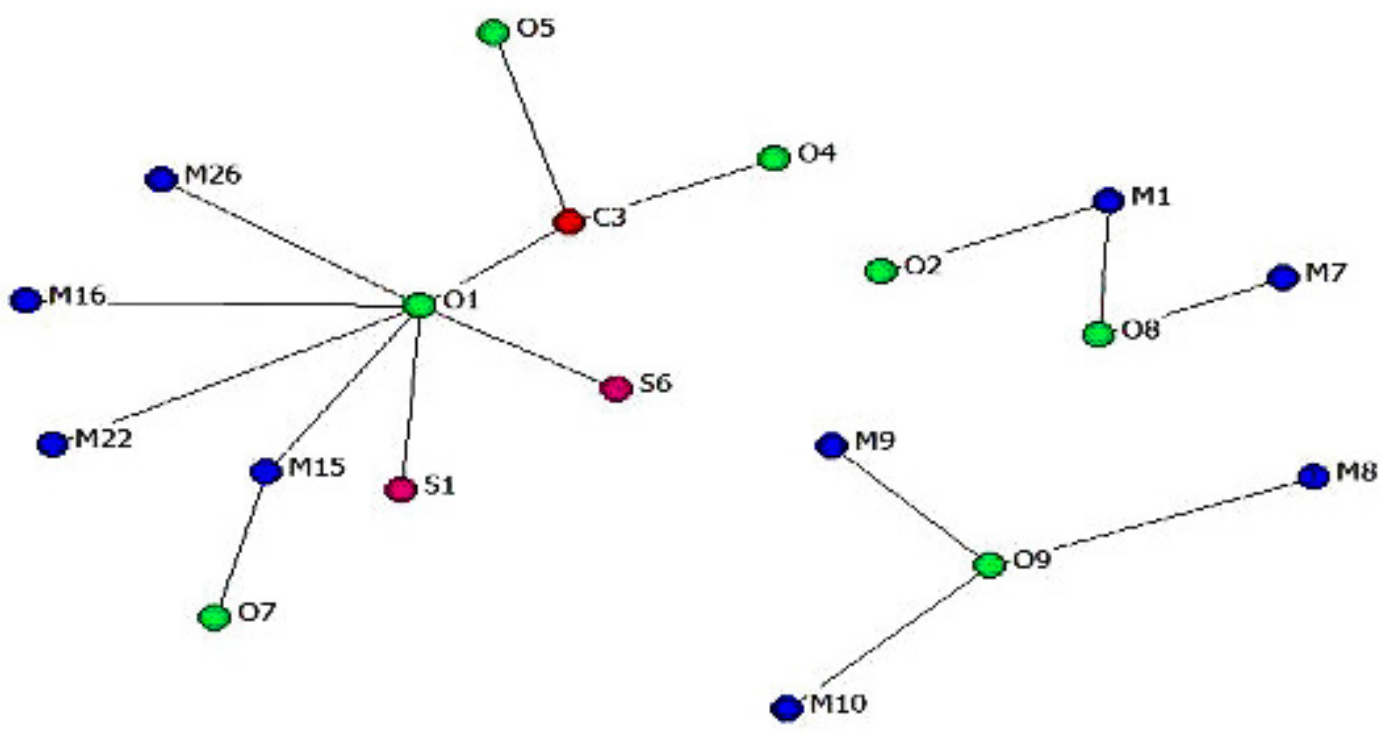

Figura 7. Esquema de la red de gestión

Fuente: Elaboración propia con base en las encuestas.

*Nota; la O representa a las organizaciones que participan en la red; la M representa los productores Muestra, la $\mathrm{C}$ representa a los productores catalogados como Cooperantes, la $\mathrm{S}$ representa a los productores que no reciben asistencia técnica y son el grupo catalogado como Sin asistencia técnica. 


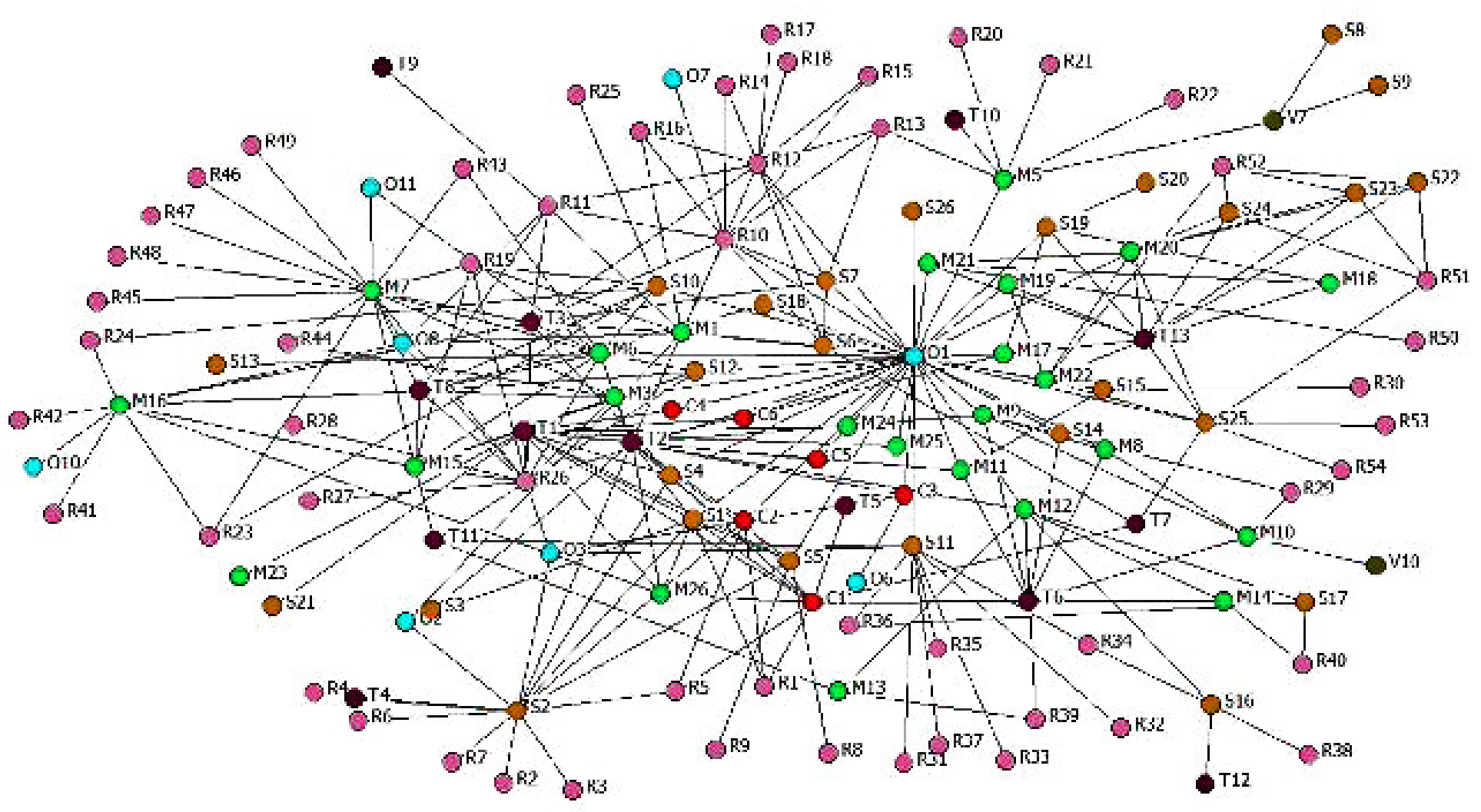

Figura 8. Esquema de la red técnica.

Fuente: Eaboración propia con base en las encuestas.

\footnotetext{
"Nota. La O representa a las organizaciones que participan en la red; la M representa los productores Muestra, la C representa a los productores catalogados como Cooperantes, la S representa a los productores que no reciben asistencia técnica y son el grupo catalogado como Sin asistencia técnica, la $\mathrm{R}$ representa al grupo de productores catalogados como Referidos, la $\mathrm{T}$ representa a los asesores técnicos o PSP, la V representa a los comercializadores que participan en la red de análisis.
}

La subred de gestión se compone de 19 actores y una densidad de $9.36 \%$. La red de gestión se compone por un número mucho menor de actores, pero la mayor densidad de las redes analizadas en este estudio. Precisamente, la densidad brinda una idea de la fortaleza de esta red en comparación con otras redes identificadas en la región. Sin embargo, el número de actores que participa, comparada con la red total, indica que se pueden orientar esfuerzos y mecanismos que incorporen otros actores para incrementar los beneficios para los actores de la red.

La subred técnica se integra por 132 actores y una densidad de 5.49\%. En este caso, los comercializadores y los técnicos forman parte fundamental de esta subred. Las ins- tituciones de investigación y las dependencias gubernamentales involucradas en la transferencia de tecnología forman parte fundamental de la red.

\section{Vínculos entre las subredes}

Las interacciones entre grupos de productores en la red se estiman a partir de una simulación para identificar qué tipo de productores son los más importantes dentro del flujo normal de información en la red.

Así, si de la red tecnológica se eliminan los productores Cooperantes, los actores permanecen unidos entre sí, lo que indica que estos productores no son tan relevantes en el proceso de la gestión de la innovación. 
Esto quiere decir que, ante un programa de intervención, los productores de Cooperantes no serán trasmisores de información para el resto de la red, pero si podrán ser adoptantes.

Por otra parte, si los productores Muestra se eliminan, el $18.82 \%$ de actores de la red dejarían de obtener información; entonces, los productores Muestra son valiosos para la adopción de innovaciones.

Si de la red se eliminan las dependencias de gobierno, las relaciones entre productores no se rompen; por tanto, si bien los programas gubernamentales inciden y fuerzan a que el productor adopte innovaciones, otras fuentes de información podrán remplazar la presencia de estas para adoptar innovaciones. En el caso de los productores Referidos, al ser tan pocos los entrevistados no existe suficiente información para realizar un análisis completo.

En el entendido que los productores de la categoría Sin asistencia técnica, el flujo de información, regularmente, proviene de los productores referidos, se tiene que 15 nodos dejan de participar en la red; por tanto, no existe suficiente información para con- cluir. La recomendación es continuar con este estudio para completar la información y aportar más elementos de análisis con este grupo.

Mientras que el efecto del programa gubernamental dentro del flujo de la red indica que es importantes, ya que la cantidad de relaciones (grados de entrada) que establecen con los productores, donde fungen como pioneros de información más no como elementos básicos para la distribución de la información, es muy importante para el funcionamiento de la red técnica.

\section{Indicadores de intermediación y centralidad}

Una de las razones para considerar la importancia de un actor recae en su intermediación; el dato se enfoca en el control de la comunicación. La intermediación se define como la posibilidad de un nodo para intermediar las comunicaciones entre los otros (Aguilar et al, 2010). En otras palabras, la intermediación es el número de veces que un actor está en camino más corto entre dos actores.

TABLA 3.

Grados de intermediación entre las subredes.

\begin{tabular}{|c|c|c|c|c|c|}
\hline \multirow{2}{*}{$\begin{array}{l}\text { Grupo de } \\
\text { productores }\end{array}$} & \multicolumn{5}{|c|}{ Grados de intermediación (\%) } \\
\hline & General & Con asistencia técnica & Sin asistencia técnica & Comercial & Gestión \\
\hline Subgrupo Muestra & $56.10 \%$ & $7 \%$ & $5 \%$ & $0.6 \%$ & $0 \%$ \\
\hline $\begin{array}{l}\text { Subgrupo } \\
\text { Cooperantes }\end{array}$ & $63.84 \%$ & $5 \%$ & $1 \%$ & $0 \%$ & $0 \%$ \\
\hline $\begin{array}{l}\text { Subgrupo } \\
\text { Referidos }\end{array}$ & $3.03 \%$ & $1 \%$ & $1 \%$ & $0 \%$ & $0 \%$ \\
\hline $\begin{array}{l}\text { Subgrupo Sin } \\
\text { asistencia técnica }\end{array}$ & $12.34 \%$ & $3 \%$ & $2 \%$ & $0 \%$ & $0 \%$ \\
\hline
\end{tabular}

Fuente: Elaboración propia con base en los resultados de las encuestas. 
Mientras los productores Cooperantes y Muestra aparecen con mucha frecuencia dentro de la red, entendiendo que son éstos quienes sirven como "puentes" para la transmisión de la información, los productores Referidos y Sin asistencia técnica son "poco" relevantes para la gestión de la innovación. Este dato coincide, precisamente, con que productores Cooperantes y Muestra son beneficiarios del programa de gobierno.

Asimismo, los productores que no reciben la asistencia técnica son quienes en menor medida participan en la adopción de innovaciones, siendo más bien observadores de lo que sucede a su alrededor y esperando un ejemplo validado para generar información y trasmitirla a otros productores. En cuanto a la subred comercial y de gestión se observa que no existe una estructura de red consolidada, situación que abre el abanico de oportunidades para impulsar el desarrollo en estas áreas con programas de gestión.

En lo que corresponde a la red comercial, las relaciones establecidas con los compradores individuales indican el flujo comercial de ganado, sin embargo, lo que se observa en la red comercial no existe una organización para impulsar ventas consolidadas, lo que indica que es necesario que la asesoría técnica se oriente también a la organización de productores y el fomento de actividades en común. En este sentido, las relaciones de productores con los vendedores son del $67.11 \%$, mientras que del total de productores $13.16 \%$ de los productores exportan su ganado.

La red de gestión tiene como principal actor a la SAGARPA (43.755\%), misma que tiene múltiples programas de apoyo directo al campo; existe, además, la presencia también de otras instituciones gubernamentales.

\section{Posición de los actores en la red tecnológica}

Como ya se ha mencionado antes, uno de los objetivos principales del presente estudio es explicar el proceso de la gestión de las innovaciones en la cadena de valor de bovinos carne, por lo que resulta necesario analizar, con mayor detalle, el papel de los actores en la red tecnológica; es decir, a todos aquellos actores con vínculos encaminados al intercambio de información, la cual se traduce en la adopción de innovaciones. Aunque a dicha red se le denomina tecnológica, no sólo se considera el intercambio de información de carácter estrictamente técnico, sino también toda la relacionada con los temas de organización, administración y gestión ambiental.

$\mathrm{Al}$ considerar la totalidad de nexos entre los actores de la red tecnológica se encuentra que, del total de relaciones en cuanto a la adopción de innovaciones, el 50.35\% de las relaciones posibles se dan entre los mismos productores, mientras que en las relaciones entre el productor y los técnicos se dan $28.12 \%$.

Considerando que el grupo de productores Referidos fue el más numeroso de acuerdo al modelo de "bola de nieve", y considerando que no todos los productores referidos fueron partícipes en reportar las fuentes de innovación, se observa nuevamente la importancia del programa gubernamental como actor importante en la gestión de innovaciones.

La difusión del aprendizaje depende que el productor esté convencido de llevarla a cabo, principalmente si precisamente si primero se observa con otro que sea innovador o cooperante. Puede decirse que aprenden del ejemplo y una vez que observan que existen resultados tangibles y, sobre todo que no sean onerosa su aplicación en su unidad de producción pecuaria. 
TABLA 4.

Fuentes de relaciones de intercambio de innovaciones.

\begin{tabular}{llllll}
\hline Fuentes de información & Cooperantes & Muestra & Referidos & $\begin{array}{l}\text { Sin asistencia } \\
\text { técnica }\end{array}$ & $\begin{array}{l}\text { Concentración de } \\
\text { las relaciones (\%) }\end{array}$ \\
\hline $\begin{array}{l}\text { Subgrupo Muestra } \\
\text { Subgrupo Cooperantes }\end{array}$ & $0.00 \%$ & $6.25 \%$ & $1.74 \%$ & $4.51 \%$ & $12.50 \%$ \\
$\begin{array}{l}\text { Subgrupo Referidos } \\
\text { Subgrupo }\end{array}$ & $1.39 \%$ & $0.35 \%$ & $0.00 \%$ & $0.69 \%$ & $1.39 \%$ \\
$\begin{array}{l}\text { Sin asistencia técnica } \\
\text { Técnicos }\end{array}$ & $0.35 \%$ & $11.46 \%$ & $5.21 \%$ & $13.19 \%$ & $31.25 \%$ \\
$\begin{array}{l}\text { Dependencias } \\
\text { Compradores de ganado }\end{array}$ & $0.04 \%$ & $1.74 \%$ & $2.08 \%$ & $5.21 \%$ \\
\hline
\end{tabular}

Fuente: Elaboración propia con base en los resultados de las encuestas.

Es importante que se trabaje de manera sustancial en la organización de productores, siendo el reto que los actores presentes en el sector pecuario deberán tener como prioridad para impulsar el crecimiento sostenido y firme del sector pecuario.

Esta organización de productores deberá acompañarse de gestiones para que sean sujetos de apoyo para subsidios, financiamiento, créditos, y demás actividades que permitan la inserción en el mercado de estos grupos con el poder de negociación lo suficiente que logren mantenerse de manera constante en la red de valor.

La inversión de bienes públicos en el sector pecuario deberá impactar de manera significativa en la adopción de innovaciones por parte de los productores.

La red de valor requiere que se busquen alternativas de diversificación económica. Además, urge que se busquen alternativas para fortalecer el cuidado y conservación de los recursos naturales, ya que el agostadero es sin duda el alimento más barato del ganado.

Tanto la innovación como su adopción dependen de fuentes diversas resultantes de un intercambio múltiple de información.

\section{Conclusiones}

Aun cuando los atributos (como edad, escolaridad, superficie dedicada a la actividad, infraestructura productiva en la UPP, inventario ganadero) del productor afectan de manera significativamente la adopción de innovaciones, no siempre éstas determinan el nivel de capacidad que el productor sea receptivo a escuchar mejoras, ya sea por el asesor técnico, por el proveedor de insumos y maquinaria.

El impacto de la asistencia técnica y el programa de desarrollo de capacidades está dado en este caso por el hecho que quienes reciben la asesoría técnica y capacitación son quienes al momento realizan mayor cantidad de innovaciones, son también la principal fuente de conocimiento, son también quienes desde su llegada con los grupos apoyados han incrementado de manera sustancial el mejoramiento de las condiciones tecnológicas. Asimismo, las innovaciones propuestas han incrementado en las UPP's desde que el programa inició su operación. 


\section{REFERENCIAS}

Aguilar, J., Altamirano, J., Rendón, R. (Coords.) y Santoyo, V. (Ed.) (2010). Del extensionismo agrícola a las redes de innovación rural. Texcoco: Universidad Autónoma Chapingo.

Bonilla, E., Cardeño, E. y Cardeño, N. (2015). La función financiera en las micros, pequeñas y medianas empresas, del municipio de Riohacha. Económicas CUC, 36(2), 137-146. Disponible en https://revistascientificas.cuc.edu. co/economicascuc/article/view/762

Borbón-Morales, C. (Coord.) (2011). Diagnóstico del sector agropecuario y pesquero del estado de Sonora. Hermosillo: Centro de Investigación en Alimentos y Desarrollo.

Chumaceiro, A, Hernández, J., Meléndez, Y. y Acurero, M. (2017). Responsabilidad universitaria y sociedad del conocimiento para la generación de competencias TIC. En, A, Chumaceiro, F. Ramos y J. Hernández (Ed), Procesos formativos para el siglo XXI. Cabimas: Fondo editorial UNERMB. Disponible en https://www.researchgate.net/publication/322686889_PROCESOS_FORMATIVOS_PARA_EL_SIGLO_XXI

Cooke, P., Roper, S. \& Wylie, P. (2003). The Golden Thread of Innovation and Northern Ireland's Evolving Regional Innovation System. Regional Studies, 37(4), 365-379. http://dx.doi. org/10.1080/0034340032000074406

Cotec. (2006). La persona protagonista de la innovación. Madrid: Fundación Cotec para la Innovación Tecnológica.

Dorf, R. (2001). Technology, Humans, Society: Toward a Sustainable World. Cambridge: Academic Press.

Engel, P. y Salomon, M. (1999). Facilitando la innovación para el desarrollo. Una caja de recursos para el ERISCA. Santiago de Chile: RIMISP.
Esser, K., Hillebrand, W., Messner, D. y Meyer-Stamer, J. (1996). Competitividad sistémica: nuevo desafío para las empresas y la política. Revista CEPAL, (59), 39-52.

Freeman, L. (2004). The Development of Social Network Analysis. A study in the Sociology of Science. Vancouver: Empirical Press.

Hartwich, F. y Ampuero, L. (2009). Alianzas para la innovación: aprendizajes desde Bolivia. Revista Pueblos y Fronteras digital. 6(1), 1-38.

Hernández, J. y Chumaceiro, A. (2018). Acercamiento histórico a la participación ciudadana en Venezuela: Modelo de relación Estado-Sociedad (19582012). Revista de Ciencias Sociales (RCS), 24(2), 56-67. Disponible en https://produccioncientificaluz.org/index.php/rcs/article/view/24819/25349

Inifap. (2010). Informe final 2009-2010 de la Unidad Técnica Especializada Pecuaria de la Estrategia de Asistencia Técnica Pecuaria en Sonora. Hermosillo: INIFAP.

Lamprinopoulou, C., Renwick, A., Klerkx, L., Hermans, F. \& Roep, D. (2014). Application of an integrated systemic framework for analyzing agricultural innovation systems and informing innovation policies: Comparing the Dutch and Scottish agrifood sectors. Agricultural Systems, 129(1), 40-54. $\quad$ https://doi.org/10.1016/j. agsy.2014.05.001

Leeuwis, C., y Van den Ban, A. (2004). Communication for rural innovation: Rethinking agricultural extension (3 ed.). Oxford: Blackwell Science.

López, R. M., Solís, G., Murrieta J. y López R. (2010). Percepción de los ganaderos respecto a la sequía. Viabilidad de un manejo de los agostaderos que prevenga sus efectos negativos. Estudios Sociales, (Número Especial), 222-241. 
Lundvall, B. (2011). Notes on innovation systems and economic development. Innovation and Development, 1(1), 25-38. https://doi.org/10.1080/21579 30X.2010.551064

Meraz, E. y Zárate, J. (2002). Diagnóstico de la ganadería bovina del sur de Sonora. Obregón: UACH-CRUNO.

Muñoz, R. y Santoyo, C. (2010). Del extensionismo a las redes de innovación. En, J. Aguilar, J. Altamirano y R. Rendón (eds.), Del extensionismo a las redes de innovación (pp. 31-69). Chapingo: Universidad Autónoma Chapingo-CIESTAAM.

Muñoz, R., Rendón, R., Aguilar, J., García, J. y Altamirano, J. (2004). Redes de innovación, un acercamiento a su identificación, análisis y gestión para el desarrollo rural. Morelia: Fundación Produce Michoacán AC, Universidad Autónoma de Chapingo.

Ramírez-García, A. G. (2013). Giras de intercambio: Una estrategia de enseñanza de productor a productor. [Boletín Sonora. No. 10]. Sonora: Centro Estatal de Capacitación y Seguimiento de la Calidad de los Servicios Profesionales para el Desarrollo Rural del estado de Sonora.

Ramírez-García, A. G. (2012). Informe de actividades del Centros Estatal de Capacitación y Seguimiento a la Calidad de los Servicios Profesionales para el Desarrollo Rural del estado de Sonora.Sonora: Centro Estatal de Capacitación y Seguimiento de la Calidad de los Servicios Profesionales para el Desarrollo Rural del estado de Sonora.
Ramírez-García, A. G. (2011). Informe de actividades del Centros Estatal de Capacitación y Seguimiento a la Calidad de los Servicios Profesionales para el Desarrollo Rural del estado de Sonora. Sonora: Centro Estatal de Capacitación y Seguimiento de la Calidad de los Servicios Profesionales para el Desarrollo Rural del estado de Sonora.

Rendón, R., Aguilar, J., Múñoz, M. y Reyes, J. (2007). Identificación de actores clave para la gestión de la innovación: El uso de redes sociales. Chapingo: Agencia para la Gestión de la Innovación. Universidad Autónoma Chapingo-Ciestaam/PIIAI.

SAGARPA. (2012). Reglas de Operación del Programa de Desarrollo de Capacidades, Innovación Tecnológica y Extensionismo Rural. [Online]. Disponible en http://dof.gob.mx/nota_to_pdf.php?fech $a=31 / 12 / 2012 \&$ edicion=MAT

Semarnat. (2014). Coeficientes de agostadero por entidad (hectárea por unidad animal). [Online]. Disponible en http://dgeiawf.semarnat.gob. $\mathrm{mx}: 8080 / i b i \_a p p s / W F S e r v l e t ? I B I F$ $\mathrm{ex}=\mathrm{D} 2$ _AGRIGAN04_06\&IBIC_ user=dgeia_mce\&IBIC_pass $=$ dgeia_ mce\&NOMBREENTIDAD=*

Spielman D., Davis, K., Negash, M. \& Ayele, G. (2008). Rural Innovation Systems and Networks. Agriculture and Human Values, 28(2), 195-212. http://dx.doi. org/10.1007/s10460-010-9273-y

Van Mierlo, B., Leeuwis, C., Smits, R. y Klein-Woolthuis, R. (2010). Learning towards system innovation: Evaluating a systemic instrument. Technological Forecasting and Social Change, 77(1), 318-334. http://dx.doi.org/10.1016/j.techfore.2009.08.004 


\title{
Biodata
}

Adan Guillermo Ramírez-García es profesor Investigador del Centro Regional Universitario del Noroeste en la Universidad Autónoma de Chapingo (México). http:// orcid.org/0000-0002-1711-5942

\section{Alejandro Ismael Monterroso-Rivas es profesor Investigador del Departamento de Suelos en la Universidad Autónoma de Chapingo (México). https://orcid.org/0000- 0003-4348-8918}

\begin{abstract}
Anastacio Garcia-Espejel es profesor Investigador del Departamento de Agroindustrias en la Universidad Autónoma de Chapingo (México). https://orcid.org/00000002-6462-6681
\end{abstract}

